the length of the incubation period was never in dispute, but was accepted as being fourteen days on an average, and this doubtless governed the finding of the jury as to Mrs. Field's case, which they gave as a "contact" case.

Another question of great importance which was asked by the jury before they retired was whether, assuming the farmer to have taken all possible precautions, that fact would affect the question of liability. Mr.. Justice Bray answered that question in a most direct and emphatic manner in the negative. This must be borne in mind when giving advice as sanitary officials in cases where infectious illness or sanitary defect exists in places where food for human consumption is sold.

\section{AN OUTBREAK OF POISON BY ARSENICAL SWEETS.*}

By J. R. HUTCHINSON, M.B., Ch.B., D.P.H., Assistant to the Medical Officer of Health, Manchester.

ON April 3 rd and $4^{\text {th }}$, I908, two letters were received by the medical officer of health from the head masters of two city schools stating that several of their scholars had been violently sick soon after eating a certain kind of sweet.

In one school ("A") twenty-four children had been taken ill, whilst in the second school ("B") nine children were affected. With the letters were sent two packets of the suspected sweets, one from each school, and the names of the shopkeepers from whom they were obtained were given.

The samples enclosed consisted of a number of irregularly rounded hard brown sweets, each somewhat larger than a marble. Some of them were quite dry, and coated with a light brown powder; whilst others were sticky, and were dark in colour. The retail price was four ounces for-one penny. One ounce contained from ten to eleven sweets. After a cursory examination both samples were submitted to Professor Délépine for analysis.

On April 6th Professor Délépine reported verbally to the medical officer of health that many of the sweets contained "a large amount of arsenic."

On April 7 th the medical officer of health visited the manufacturer, acquainted him with what had taken place, took samples of the raw material of which the sweets were made, and requested that, pending a chemical analysis, no more of these materials should be used. The manufacturer then informed the medical officer of health that the two shops from which the sweets apparently responsible for the illnesses at schools " $A$ " and " $B$ " were bought were supplied from a consignment manufactured on March 24th,

* From the Annual Report of the Medical Officer of Health, Manchester, Ig08. and delivered to six shops and one middleman in the city some time between the $25^{\text {th }}$ and the $27^{\text {th }}$ of that month. He further stated that he, too, had had a complaint from one of the shops that the sweets had caused sickness amongst the scholars of a third school ("C "), and that he had in consequence been round to the six shops supplied and recalled the whole consignment. All the recalled sweets (eleven $7-1 \mathrm{~b}$. boxes) were handed over to the medical officer of bealth, who retained one box and sent the others on to Professor Délépine.

The names and addresses of the six shopkeepers and the middleman from whom the sweets had been recalled were obtained.

The schools "A" and "B" were visited, and the history of thirty-three cases of illness were investigated. At school " $\mathrm{C}$ " fourteen cases were enquired into. Three of the six shops on the list supplied by the manufacturer are those accounted for as being responsible for the illnesses at schools "A," "B," and " $\mathrm{C}$ "; the other three were visited, as was the middleman. This latter dealer had supplied the sweets to four other shops, so that in all seven remained to be dealt with. These seven were visited in turn, and it was found that in three instances the boxes had been recalled unopened, and in two others, although the boxes had been opened, none of the sweets had been sold. In the case of the sixth shop four halfpennyworths had been sold, and, so far as the shopkeeper knew, had been consumed without any ill effects; whilst the seventh shop was found to be responsible for the illness of nine children at a fourth school ("D").

The four shops from which the sweets causing the illness at schools " $\mathrm{A}$," " $\mathrm{B}$, ," "C" and " $\mathrm{D}$ " were obtained are in close proximity to the respective schools, and may be regarded as regular school tuck shops, whilst the only other shop at which the sweets are known to have been bought is not situated near a school. It is quite possible, therefore, for the sweets bought here to have been the cause of illness without the cases coming to light, for, as will be seen later, in none of the known cases was a medical man called in.

In all, sixty-two cases of poisoning are known to bave occurred-fifty-six in children attending the schools " $A$," " $B$," " $C$ " and " $D$," five in children under school age, and one in an adult, the mother of one of the affected children.

The number of sweets consumed was usually small-one, two, three, or four. Eleven purchases, nine of 2 ozs., one of 4 ozs., and one of 1 oz., were responsible for forty-eight of the sixty-two recorded cases. What commonly happened was that when a child found that the sweets made him ill, he passed them on to some of his friends, who in turn disposed of them in the same way. The smallest quantity known to have been eaten was 
half a sweet, whilst the largest quantity was twenty sweets (halfpennyworth). In both cases severe vomiting ensued. The effects left after eating a large quantity do not appear to have been more severe or lasting than those experienced from a small number.

In nine instances only one sweet was eaten; in six there was vomiting, in two the children were ill but did not vomit, and in one case the child was not ill.

In eleven instances two sweets were eaten, ten of the children were sick, one was not sick.

In six instances three sweets were eaten; five of the children were sick, one was not sick.

In four instances four sweets were eaten, and all the children were sick.

In thirteen cases more than four sweets were eaten, and all the children were sick.

Various periods elapsed between the eating of the sweets and the onset of symptoms. Most commonly the interval was about an hour; in some cases, however, the illness came on almost immediately, whilst in others it was delayed one-and-a-half to two hours. In all cases the onset was sudden, some of the children vomiting in school before they had time to leave the room. As a rule the only symptoms were vomiting, and less frequently, abdominal pain; after the stomach was emptied the children became quickly well. In some instances there was purging; in one or two there was a general feeling of illness with giddiness. The most striking feature was the rapid and apparently entire recovery of the children, either during the same day or by the next morning. This is illustrated by the fact that of all the children affected only six missed any school period, five of these were absent for half-aday, whilst one child was away two days.

In forty-six cases vomiting was the main symptom. It occurred in seven cases within fifteen minutes of eating the sweets, in four more within thirty minutes, in eleven more within forty-five minutes, in ten more within sixty minutes, whilst in fourteen cases it was delayed over an hour. There was abdominal pain in twenty-two cases, purging in nine, headache and dizziness in six.

Boys and girls were alike affected, and only four children are positively known to have eaten sweets without any ill effects. Of these four, two ate two sweets each, and two ate one sweet each. An adult who ate two sweets was violently sick, whilst a pet dog which ate one also vomited.

That the symptoms were due to the ingestion of an irritant poison contained in the sweets in sufficient quantity to cause almost complete expulsion is proved by the fact that-

(I) They were those of an irritant poison.

(2) They occurred only in those children who had eaten this particular kind of sweet.
(3) No further illness occurred after the recall of the sweets.

(4) The illnesses were all transitory. After vomiting, the sufferers were quickly well again.

That the irritant poison was arsenic is proved by the facts that-

(1) Arsenic was found by Professor Délépine in the sweets in sufficient quantity to account for all the symptoms;

(2) No other poison was detected in them; and

(3) Arsenic was found in the urine of four of the sick children seven days after the sweets were eaten.

The fact that four children ate the sweets without their giving rise to any symptoms in no way militates against the general conclusions, for, as Professor Délépine's subsequent investigations showed, some of the sweets contained the poison whilst others did not.

By the time the clinical investigations were completed an extended report by Professor Délépine on the analysis of the two packets of sweets obtained from the schools " $A$ " and " $B$," and on the boxes of sweets recalled by the manufacturer, was at hand. Of the two packets Professor Délépine says: "The first contained twenty-seven sweets, six of these were light-brown in colour, and looked hard and dry. Of these six, three were almond-shaped, and three were irregularly rounded. These latter three resembled the remaining twenty-one, except in point of dryness; the twenty-one were dark-brown and sticky, they adhered to one another and to the paper. There were about 175 sweets to the pound." The second packet, the report goes on to say, "contained sweets having the same character as the bulk of the sweets in the first packet; there was, however, a larger proportion of small sweets, there being about 198 to the pound."

Several sweets were analysed and found to contain a large amount of arsenic. It was then observed that the six dry hard sweets in the first packet contained no appreciable amount of arsenic, whilst all the moist sticky ones were heavily loaded with the poison. Further, the arsenic was uniformly distributed throughout each of the sticky sweets, the central harder portion and the superficial softer portions containing about equal amounts. In one section Professor Délépine was unable to detect any mass of white arsenic or any recognizable crystals. $\mathrm{He}$ estimated that the quantity of the poison present was not less than 13 parts per Io,ooo, i.e., a little over 9.1 grains per lb., so that some of the larger sweets which weighed $\frac{1}{10} \mathrm{oz}$. contained probably not less than $\frac{1}{20}$ grain of arsenic.

The presence of this quantity of arsenic fully explains the symptoms, and explains, too, the 
rapidly induced vomiting. This prompt ejection of the poison would appear to have saved the children.

From Professor Délépine's examination of the two packets of sweets it is obvious that two varieties were being dealt with; the one dry, hard, light-brown in colour and non-arsenical; the other moist, soft, sticky, dark in colour, and containing approximately $\frac{1}{20}$ grain of arsenic per sweet. When the contents of the eleven recalled boxes came to be examined it was found that five of them contained sweets of the first description, four those of the second, whilst the other two contained a mixture of both kinds, some poisonous, others non-poisonous. The smell of the two types of sweet was quite different.

The amount of arsenic present, as found by Professor Délépine using the Délépine-Reinsch method, varied from $8 \cdot 4$ to $I I^{\prime} 2$ grains per $\mathrm{lb}$.

How does it happen that almost exactly onehalf the number of recalled boxes contained the poisonous sweets and the other half the nonpoisonous?

As before stated, all these sweets were made on March $24^{\text {th. }}$. On further inquiry it was ascertained that two boilings of this particular sweet were made on that date. It might reasonably be assumed, therefore, that only one boiling contained the poison. Now one boiling weighs approximately 44 lbs. From two such boilings, therefore, $88 \mathrm{lbs}$. of sweets or twelve 7 -lb. boxes ought to have been made. According to Professor Délépine's analysis, five of the boxes submitted to him contained wholly poisonous sweets, whilst two contained the mixed poisonous and nonpoisonous ones. The former were, however, much more numerous than the latter variety. The total weight of the seven boxes was $49 \mathrm{lbs}$., and if $5 \mathrm{lbs}$. be allowed for the non-arsenical sweets in the two mixed boxes, we get $44 \mathrm{lbs}$. of poisonous sweets; this corresponds to one boiling.

The average amount of arsenic found was IO-I I grains per $\mathrm{lb}$. of sweets. This means something like one ounce of the poison in the contaminated boiling.

The ingredients that go to make up one boiling were said to be: glucose rolbs., cane sugar $30 \mathrm{lbs}$., starch 6 lbs., and in addition a little cocoa-shell powder and water.

What was the source of the arsenic?

Several possibilities have to be considered. (I) One of the ingredients may have contained arsenic as a result of its process of manufacture, as, e.g., happened in the beer poisoning outbreak in 1900. (2) The poison may have been introduced with one of the ingredients having accidentally got into one of the packages. (3) It may have been accidentally introduced by some vessel or instrument previously used to contain arsenic or an arsenical compound, or (4) it may have been introduced by design.
'To understand what possibilities exist in any of these occurrences, it is necessary to know how the sweets are made.

A cask of glucose which weighs $5 \mathrm{cwts}$. is kept in the boiling room, as are sacks of starch and sugar, which when full weigh 2 to $2 \frac{1}{2} \mathrm{cwts}$. apiece. The pans used are four in number; they are heated over coke fires. The staff consists of one man, an employé of 25 years' standing, and three girls. The man is the actual "sugar boiler," whilst the three girls take each of them a part in every operation, as occasion requires. They usually mix the charge of glucose, sugar, etc, stir the pots, knead in the starch, pull the mass, roll it (that is to say, mould the sweets), and then. break them up.

Thirty lbs. of cane sugar go to one boiling. This is scooped out of the sack with a vessel used for the purpose, and kept in the sack. It is put on to a scale pan and weighed out; a hole is then made in the summit of this pile of sugar on the scale pan, and into it is placed ro lbs. of glucose.

The glucose is taken out of the cask by a girl, who picks it up in her hands after dipping them in water, rolls it in a ball in order to free it from her fingers, and then places it in the hole made in the sugar on the scale pan.

Roughly, io lbs. of glucose are added.

When the glucose cask is getting empty it is reared on edge against the wall so as to enable the girl to reach the bottom. This, of course, involves the burying of her head, arms, and shoulders in the cask. The contents of the scale pan are transferred to the boiling pan, and two quarts of water are added by means of a lading can. The mixture is then heated over a coke fire to 280 deg. F., at which temperature it is kept for 20 minutes. At the expiration of this time it is poured out on to a cooled metal slab greased with cocoa butter. When it has cooled sufficiently to allow of manipulation six pounds of starch are added to the mass and kneaded into it. The starch is added by means of a scoop kept in the starch sack. After kneading, pieces of the plastic mass are cut off and pulled by hand over a hook with the effect of lightening the colour. 'The pulled sweet is then passed between rollers, the opposing surfaces of which are hollowed out to mould the individual sweets. The sweets are then separated by breaking up the rolled cake. Any residue which may remain is swept up and put in a tin under the table to be added to the next boiling. The sweets are then dusted over with cocoa-shell powder and packed away in $7-1 \mathrm{~b}$. boxes. This, it was said, is the invariable routine.

At his visit to the factory on April $7^{\text {th }}$ the medical officer of health was given the most positive assurances that no materials other than those ordinarily used had been used for the making of the sweets on March 24th, that no 
difference had been made in the two boilings of that date, and since that date, or even before it, no raw materials have been removed from the premises. The manufacturers stated that if anything unusual had occurred in connection with the particular boilings on March $24^{\text {th }}$ they would have been informed of it ; they further stated that, so far as they knew, no arsenic or substance likely to contain arsenic was, or ever had been, on their premises. In short, they professed themselves utterly unable to account for the occurrence, and expressed their willingness to do all in their power to assist in clearing the matter up. The appearance of the sweets, and the fact that they contained a large amount of glucose, suggested to Professor Délépine the possibility that a highly arsenical glucose might have been used in their manufacture. It was found that there were on an average ten sweets to the ounce, each containing approximately $\frac{1}{20}$ grain arsenic. This is equivalent to eight grains of arsenic per pound, so that every pound of glucose used in boiling-assuming glucose to be the source of the poison-must have contained something like thirty-five grains of arsenic. This is far in excess of the quantity of arsenic found in the glucose which was responsible for the outbreak of beer poisoning in rgoo. In this material the largest quantity of poison found by Professor Délépine was six and a-half grains per pound, whilst Professor Campbell Brown found as much as nine grains per pound. Professor Délépine states, however, in his report that, considering the fact that some of the sulphuric acid used in the manufacture of arsenical glucose contained $a$ heavy precipitate of almost pure arsenic, it is quite possible that some of the samples of glucose may have contained very much larger quantities of arsenic than either Professor Campbell Brown or he disclosed. It appeared, therefore, that the introduction of arsenic by means of arsenical glucose was a possibility.

The samples of glucose, sugar, starch and cocoa-shell powder first obtained were not taken from the same packages as the materials used in the boilings of March 24th; they were, however, from the same consignments. It must be remembered that fully fourteen days had elapsed between the date of making of the poisonous sweets and the notification to the medical officer of health of the first cases of illness. All that remained, therefore, of the packages from which the ingredients used in the boilings of March 24th were taken had been used up some days previously. Nevertheless, samples of these materials were submitted to Professor Délépine, who pronounced them free from arsenic.

We may suppose that the arsenic was introduced as part of a sack of starch. Against this is the fact that only one panful of sweets was affected, and this could only have happened if the puison had been collected from the bottom of a sack, which is unlikely. Professor Délépine was unable to find any crystalline arsenic in the sweets, and, besides, both the contaminated and uncontaminated sweets were found to contain the same amount of starch. The poison could not have been introduced with the brown cane sugar without attracting attention as a white powder. The cocoa-shell powder with which the finished sweets were dusted over can be dismissed at once, as it was found that the centre of the contaminated sweets contained as much arsenic as the outer portions.

It is thus very unlikely that the poison was introduced as an accidental contamination of any of the ingredients in bulk.

The idea of the poison having been accidentally introduced through the medium of some vessel or utensil previously used to contain arsenic or one of its compounds may probably be dismissed.

It was impossible to examine the sacks used to contain starch or sugar, as they had been returned to the respective dealers in those articles, nor was it any use examining the pans, as they are used over and over again every day.

The possibility of the transference of arsenic by rats was considered, and was excluded.

In all twenty-nine samples of materials, including sweets of various kinds, glucose, starch, sugar, rat poison, dust, soot, bicarbonate of soda, tartaric acid, etc., were submitted to and examined by Professor Délépine, and were without exception found to be free from any material a mount of arsenic.

A consideration of all the particulars appeared to suggest that the most likely suppositions were, either that some highly arsenical glucose had been used or that arsenic had been added to one panful of the sweets. To take the latter suggestion first. If as much as one ounce of arsenic had been thrown into the pan whilst the mixture was boiling, or whilst the ingredients were being mixed, one would not have expected the poison to be so uniformly distributed through the sweets as was found to be the case. This point, too, was tested experimentally by Professor Délépine. In the contents of two pans made in accordance with the formula given by the manufacturers, and with their own ingredients, he added arsenic in one case before boiling, and in the other case fifteen minutes before the end of the boiling. In both cases he obtained hard dry sweets closely resembling the non-poisonous variety found in the recalled boxes. He was unable to find with the naked eye, or by means of the microscope, any trace of the poison, although the powder added contained fine octahedral crystals of arsenious acid.

Arsenic por se, therefore, does not render the sweets sticky.

There were marked differences in appearance between the poisonous and non-poisonous sweets. 
The poisonous ones were smaller and denser than the non-poisonous; they were moist and sticky, whereas the non-poisonous ones were dry and even dusty. When melted the arsenical sweets gave a pale liquid and a dark sediment. The non-arsenical ones gave a dark liquid and a light sediment.

If then, as asserted by the manufacturers, they were all made according to the same recipe, and with the same materials and rollers, the mass passing through the rollers must have been very different. But it was found that the contaminated sweets contained twice as much reducing sugar as the non-contaminated. They were not, therefore, both made according to the formula given by the manufacturers to the medical officer of health.

Would the presence of this excess of reducing sugar render the sweets soft and sticky? Professor Délépine was able to show without doubt that it would.

We have therefore to consider whether, along with an excess of glucose introduced into one boiling of the sweets, there was also the introduction, accidental or by design, of a large quantity of arsenic.

If glucose was the source of the poison, how was it that only one panful of sweets was affected? Assuming that an experimental trial was made with a new sample of glucose just sufficient for one boiling, then this sample must have contained about one ounce of arsenic.

Confectioners' glucose is supplied mainly by two large firms in this country, one an English and the other an American company. The glucose in this instance was said to have been supplied by the American firm. Control samples of their glucose were found to be arsenic free. Besides, no special precautions were taken by this firm when they were informed of these cases of poisoning, and the Local Government Board have no knowledge of any further cases occurring elsewhere.

The presence of a double quantity of glucose plus arsenic in the sweets, then, might have been a mere coincidence. If so, it was a very remarkable one.

In view of the conflict of evidence as to the composition of the sweets, the manufacturer was again interviewed. He adhered absolutely to his former statements as to the composition of the sweets and the sources of the raw materials. Amongst other questions he was asked:-

I. Were all these sweets made with the same mould? If so, how is it that, although the arsenical sweets are denser than the non-arsenical ones, there are at least twentythree more of the latter to the pound than of the former? The first part of the question was answered in the affirmative, whilst he professed himself unable to account for the differences in weight.
2. Were the sweets by any chance obtained from an outside source? Answered in the negative.

3. How does he account for the difference in smell of the good and bad sweets? Answered he was unaware of it.

4. Did he observe any moist appearance about any of the boxes when he packed the sweets? Answered in the negative.

5. Has he questioned the "sugar boiler" as to whether any unusual circumstance had been observed about this panful of sweets? Answer: Yes, nothing had been noticed.

6. Was arsenic or any substance which might be suspected of containing arsenic kept on the premises. Answer: No.

The manufacturer repudiated the suggestion that some arsenical substance might have been removed from the premises. He stated, too, that absolutely no change had been made in the personnel of the establishment since this occurrence, nor had the routine work been altered in any way.

It follows from this that either the manufacturer himself was being grossly deceived or was not telling the truth.

These inquiries are incomplete, in so far as they do not settle the question of how the arsenic got into the sweets. They do show beyond doubt that the composition of the sweets was not in accordance with the recipe given.

One can only suspect that this is not the only particular in which misleading statements were made, and that material facts were being suppressed.

The outbreak is important, not only on account of the very large total amount of poison present, but as showing also the precise effect of known poisonous doses of arsenic on sixty-two different individuals. The usual medicinal dose of arsenic is equivalent to that contained in one of the contaminated sweets, but many of these children ate four, six, eight, ten or more. One child certainly ate twenty sweets within three and a-half hours; she was violently sick. In this case, too, the sweets were obtained from a mixed box of contaminated and uncontaminated ones. The former certainly outnumbered the latter, but it is impossible to gauge the total amount of arsenic which the child consumed. Curiously enough this was one of the children who missed no school period.

The outbreak further brings into sharp contrast the difference between acute and chronic arsenical poisoning. In the one case you get vomiting and diarrhœa, with rapid and complete recovery; whilst in the other you get the symptoms of a cold in the head, with anæmia, pigmentation, tingling in the hands and feet, muscle atrophy, and extreme helplessness, which lasts for months, and perhaps a fatal result. 